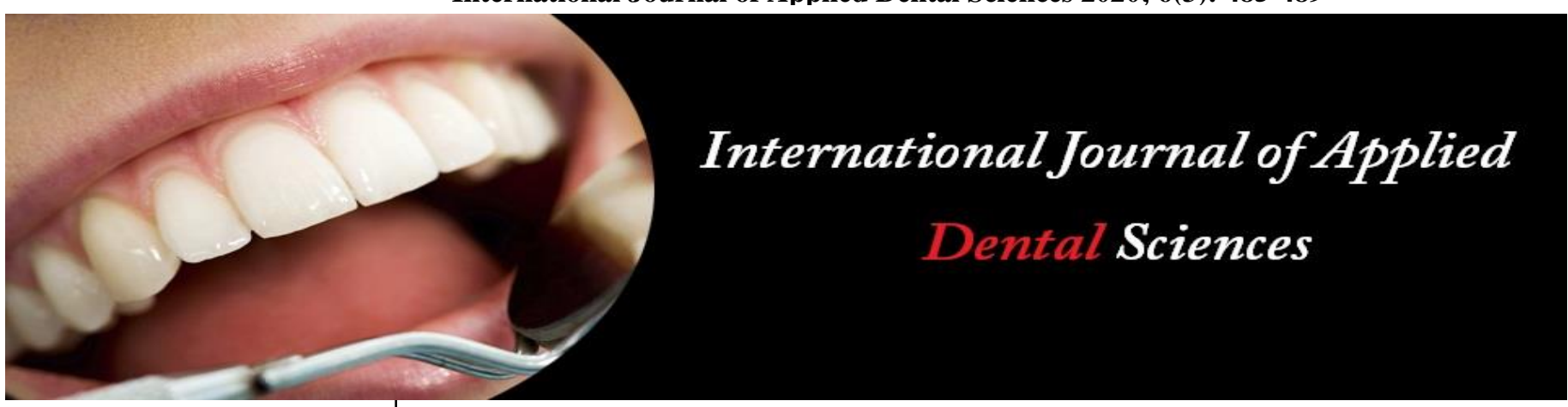

ISSN Print: 2394-7489

ISSN Online: 2394-7497

IJADS 2020; 6(3): 485-489

(C) 2020 IJADS

www.oraljournal.com

Received: 25-03-2020

Accepted: 02-05-2020

Ahmed Hassan Kamil Mustafa Assistant Professor, Department of Maxillofacial Surgery and Diagnostic Sciences, College of Dentistry, King Saud Bin Abdulaziz University for Health Sciences, Riyadh, Saudi Arabia

Corresponding Author: Ahmed Hassan Kamil Mustafa Assistant Professor, Department of Maxillofacial Surgery and Diagnostic Sciences, College of Dentistry, King Saud Bin Abdulaziz University for Health Sciences, Riyadh, Saudi Arabia

\section{A review of the aetiology of oral cancer in the Sudan}

\author{
Ahmed Hassan Kamil Mustafa
}

DOI: https://doi.org/10.22271/oral.2020.v6.i3h.997

\section{Abstract}

Objectives: To focus the light on the aetiology of oral cancer in the Sudan. Numerous reports have shown that the incidence of oral cancer worldwide is on increase. The rising incidence of oral cancer, with the absence of the well established risk factors, has wrung alarm bells.

Material and Methods: Website search (Pubmed central and google scholar) for publications addressing the aetiology of oral cancer in the Sudan, in addition to snuff dipping (Tombak) which is a common habit in Sudan.

Results: During initial search 420 publications were identified, on exclusion of studies related to other countries and other body tumours 36 studies discussing the aetiology of oral cancer in the Sudan were examined.

Conclusions: Toombak is the major contributing factor for oral cancer in the Sudan. The role of other contributing factors such as viruses other than Human Papilloma Virus, other types of tobacco such as smoked tobacco and alcohol still need more investigations.

Keywords: Aetiology, Sudan

\section{Introduction}

Oral cancer (OC) which includes cancers of the lip, tongue and rest of the oral cavity, but not cancers of the major salivary glands ${ }^{[1]}$, is responsible for considerable morbidity and mortality rates worldwide especially in developing countries. While it is estimated that cancer incidence 14 million new cases, oral cancer alone contributes to about 300.000 deaths $(2.1 \%)$ annually with $1.8 \%$ mortality worldwide ${ }^{[2,3]}$.

Oral cancer in Sudan is the sixth most common cancer amongst all cancers types (6.1 per 100.000) ${ }^{[4]}$. This is mainly attributed to the use of local type of smokeless tobacco (SLT) known as Toombak, which is popular in the Sudanese community. Toombak is made from finely ground leaves of Nicotiana rustica, and is mixed with natron or atron (sodium bicarbonate) and water. Natron or atron is probably added to Toombak for its alkaline effect and for fast absorption of nicotine to the central nervous system. Most of the oral cancer cases and deaths due to the individual susceptibility, linked to specific genetic attributes and exposure to carcinogens brought about by lifestyle behaviors ${ }^{[5]}$. The oral cavity is easily accessible for self or clinical examination to detect lesions that are potentially malignant which facilitate detection and diagnosis of the oral cancer. Subsequently, this can lead to substantial reduction of the diagnostic delays of oral cancer which estimated to be $50 \%$ of cases ${ }^{[6-7]}$.

The purpose of this study was to focus the light on the aetiological aspects and risk factors of oral cancer in the Sudan.

Materials and methods: During initial search in pubmed central and google scholar using the phrase the etiology of oral cancer in the Sudan for the period 2015-2020 about 420 articles were detected on exclusion of studies related to other countries and other body tumours, 36 studies were related to oral cancers in the Sudan

Keywords: (("etiology"[Subheading] OR "etiology"[All Fields] OR "causality"[MeSH Terms] OR "causality"[All Fields]) AND ("mouth neoplasms"[MeSH Terms] OR ("mouth"[All Fields] AND "neoplasms"[All Fields]) OR "mouth neoplasms"[All Fields] OR ("oral"[All Fields] AND "cancer"[All Fields]) OR "oral cancer"[All Fields])) AND ("sudan"[MeSH Terms] OR "sudan"[All Fields]). 


\section{Aetiology and risk factors for oral cancer in the Sudan}

Expert committees of the International Agency for Research on Cancer reviewed epidemiological studies from different countries who indulge in smokeless tobacco use and concluded that (the use of snuff can cause cancer in humans, and that the use of chewing tobacco may increase the risk for oral cancer development) ${ }^{[8]}$. In the Sudan oral snuff known locally as Tombak is made from ground leaves of Nicotina rustica,a tobacco species with high content of nicotine and minor alkaloids.This tobacco is mixed with natron or atron (sodium bicarbonate), then water is added to this mixture after 2 hours this mixture is called (Saffa) ${ }^{[9]}$. Atron is believed to accelerate the absorption of nicotine from Tombak to central nervous system ${ }^{[10]}$. The study by Idris et al. ${ }^{[11]}$ have analyzed the Tobacco Specific Nittrose Amine (TSNA) levels in Tombak and found unusually high levels of these TSNAs compared to the reported levels in any snuff ${ }^{[12,13]}$. The high levels of TSNAs found in Tombak were partially attributed to the use of tobacco Species, Nicotiana rustica, and fermentation of Tombak at elevated temperature, prolonged storage, and contamination during processing [13, 14]. Therefore, assuming chronic Tombak use, the minimum daily dose of NNK (4-(methylnitrosamino)-1-(3pyridyl)-1butanone to which these users were exposed was $0.12-0.44$ $\mathrm{mg}$. This is the highest documented uptake of a non occupational carcinogen ${ }^{[15]}$.

Epidemiological studies suggests that Tombak is a risk factor for cancer of the oral cavity and possibly of the oesophagus in the Sudan ${ }^{[16-17]}$. Several studies from Sudan have proved that Tombak use is a major risk factor that responsible of high frequencies of potential malignant oral lesions and oral cancers and in particular OSCCs in the Sudan. Most of tumours developed at the site of dip application (lower lip). Oral cancer seems to be gender-specific, as the majority of cases were males ${ }^{[18-19]}$.

Tobacco smoking has been incriminated as a predisposing factor for cancer including cancers of the oral cavity, this has been linked to specific genetic characteristic and exposure to carcinogens available in tobacco. Tobacco carcinogenicity has been documented and about one fourth of oral cancer cases are attributable to cigarette smoking ${ }^{[20]}$. Investigations found that more than 60 carcinogens are present in cigarette smoke and at least 16 in unburned tobacco have been identified. The most important are tobacco-specific nitrosamines, such as 4(methylnitrosamino)-1-(3pyridyl)-1-butanone (NNK) and Nnitrosonornicotine (NNN), polycyclic aromatic hydrocarbons $(\mathrm{PAH})$, such as benzopyrene, and aromatic amines. In particular, NNK, NNN and PAH have been causally linked to oral cancer. The activity of carcinogens is generally exerted through DNA adducts ${ }^{[21,22]}$. A cross-sectional survey of a random population sample of 4,535 households was performed, as the first survey on tobacco in the Sudan. Of the 23,367 household members identified, 21,648 (92.6\%) eligible individuals were questioned about tobacco use. Results showed that, among children and adolescents (4 - 17 years) prevalence of tobacco use was quite low (2\%, range 1 $2 \%$ ), but there was an abrupt increase up to $25 \%$ in late adolescence. Among the adult population aged 18 years and older the prevalences of toombak use (34\%) and cigarette smoking (12\%) among males were significantly higher than among females (2.5 and $0.9 \%$, respectively) ${ }^{[23]}$. Based on these studies, smoked tobacco has a role in aetiology of oral cancer, but how far this is contributing in oral cancer in Sudan and how far it is significant is unknown, since there is lack of data in this context.
There is an association between regular alcohol consumption and an increased risk for oral cancer. Such association is dose dependent. Indeed, among individuals consuming 4 - 5 drinks daily, the risk for cancer of the oral cavity is $2-3$ folds higher than among non-drinkers [24-25]. Heavy alcohol drinking contributes to $7-19 \%$ oral cancer cases ${ }^{[20,26]}$. The features of cytological atypia were verified among 10 individuals, including 5 smokers, 2 alcohol users, 2 hot meals and peppers consumers, and one non-exposed ${ }^{[27]}$. No available data about alcoholic consumers in the Sudan, because approximately 95\% of the habitual use to drink in hide, since it is considered as illegal and social stigma. As a consequence the association between alcohol consumption and the magnitude of effect as an aetiological factor for oral cancer in the Sudan can not be estimated. Genetic factors have been implicated in many cancers including oral cancer. There is scarcity of studies dealing with the investigation of association between genetic factors and level of risk for development of oral cancer in Sudan. In a study aiming to explore possible range of gene expression profiles in head and neck squamous cell carcinomas (HNSCC) and pair wised normal controls from Sudanese $(n=72)$ and Norwegian $(n=45)$ patients using a $15 \mathrm{~K}$ cDNA microarray and to correlate the findings with clinicopathologic variables. Differences in gene expression between tumour and nontumour tissues were identified in HNSCCs (Head and Neck squamous cell Carcinomas). Analysis of the two population groups revealed a common set of 73 genes within three main biological pathways. This indicates that the development of HNSCCs is mediated by similar biological pathways regardless of differences related to race, ethnicity, lifestyle, and/or exposure to environmental carcinogens. Interestingly, there was a valuable association of gene expression signature found with toombak use and anatomic site of the tumours ${ }^{[28]}$. The prevalence of mutations in exons 2 and 3 of the S100A4 gene was analyzed in the 14 OSCCs from toombak-dippers and in 25 cases of OSCCs (Oral Squamous Cell Carcinomas) from the control nonsnuff-dippers. Of the 14 OSCCs investigated from toombakdippers, mutations in the p21waf1 exon 2 were found in $43 \%$ (6 out of 14), compared to $14 \%$ ( 2 out of 14 ), $22 \%$ ( 6 out of 27) and $14 \%$ (5 out of 35) found in those from nonsnuffdippers from the Sudan, Scandinavia and the USA/ UK, respectively ${ }^{[29]}$. In another study, 9 genes related to apoptosis, cell cycle regulation and intermediate filament proteins were selected and their differential expression status was examined by real-time quantitative RT-PCR in 26 samples of Sudanese OSCCs and their matched normal controls. The findings were correlated with the habit of toombak use. The mRNA levels of $\mathrm{Bcl} 2$, keratin 1, keratin 13 and p53 were significantly lower and the level of survivin was significantly higher in the OSCC samples of the toombak users compared to their paired control samples. A significant down-regulation in keratin 1 and keratin 13 expression levels was found in the OSCC samples of the non-toombak users compared to their normal control samples. The differential expression of genes related to apoptosis, cell cycle regulation and types I and II keratin could be useful diagnostic markers and provide valuable information for the understanding of oral malignancy in relation to toombak use ${ }^{[30]}$.

A recent study from Sudan reported the presence of HPV in head and neck cancers (HNCs) in general and in oral in particular. The study was performed on 150 samples of patients diagnosed with HNSCs. Six of the $150(4 \%)$ HNSCCs were HPV positive. HPV16 was the most prevalent type, with single infections present in $3 / 6(50 \%)$ cases, 
whereas HPV18 and HPV33 were detected in 2/6 (33\%) and $1 / 6(17 \%)$, respectively. HPV infections were detected in 3 $(50 \%)$ cases of oral cavity and $3(50 \%)$ cases of pharynx ${ }^{[31]}$.

Besides tobacco and alcohol, other risk factors have been studied in relation to oral cancer in Sudan. Among these factors, diet and nutrition have been suggested to play an important role ${ }^{[32]}$. So far there is a lack of studies focusing on the prevalence of a wide spectrum of oral mucosal lesions (OML) in patients with dermatologic diseases. This is noteworthy as skin lesions are strongly associated with oral lesions and could easily be neglected by dentists. A study from Sudan found that OML were frequently diagnosed in skin diseased patients and varied systematically with age, gender, systemic condition and use of toombak [33]. Epidemiological studies conducted in various populations reported an inverse association between intake of fruit and vegetables and the risk of cancer of the oral cavity ${ }^{[34]}$.

Human papilloma virus (HPV) has been considered as a potential risk factor for oral squamous cell carcinoma (OSCC). HPVDNA have been detected in considerable proportions of oral cancers with prevalence in oral tissues varying from $0 \%$ to $100 \%[35,36]$. This variation reflects inherent variations in different populations and detection methods used ${ }^{[37,38]}$. Ibrahim et al. found that there is an association between HPV16 and 18 infections and oral squamous cell carcinoma in different regions of Sudan ${ }^{[39]}$. Oral HPV infection may be associated with different diseases of oral cavities. HPV is one of the most prevalent infections in the world with several new cases diagnosed every year ${ }^{[40]}$. HPVs are small DNA viruses with about 7900 nucleotide bases long ${ }^{[41]}$. There are more than 120 genetically different, yet closely related HPVs that are referred to as genotypes. By definition, each type is defined by having less than $90 \%$ DNA base pair homology with any other identified HPV type. The genotypes are numbered in the order of their discovery ${ }^{[42]}$. The HPV genome encodes DNA sequences for six early (E1, E2, E4, E5, E6, and E7) proteins associated with viral gene regulation and cell transformation, two late (L1 and L2) proteins which form the shell of the virus, and one region of regulatory DNA sequences. The different HPV types are characterized by genotypic variations in the DNA basesequences of E6 and E7. It is these genotypic differences that permit stratification of the virus oncogenic phenotype into high, intermediate-, and low-risk types ${ }^{[40]}$. In the case of high-risk HPV infection and under favourable conditions, the viral genome is integrated into the host genome, which is the necessary event for the keratinocytes immortality. During this process of integration, the circular form of viral genome breaks at the level of the E1 and E2 regions, never at the level of the E6 or E7 region. Different studies have shown that the integrated part of the genome corresponds to E1, E6, and E7, while the regions from E2 to E5 are lost and are not transcribed in the tumours. The loss of E2 during this process of integration produces the loss of E6 and E7 control. Therefore, the sequences E6 and E7 are directly involved in the cellular cycle by inhibiting the normal functions of p53 and $\mathrm{pRb}$, respectively. The protein $\mathrm{p} 53$ is known as the "genome's guard" and in the case of DNA damage, the p53 can provoke the arrest of cellular division and assure the time necessary for DNA repair. If damage cannot be repaired, p53 is able to induce the programmed cellular death and prevent the propagation of DNA damage in subsequent generations of cells. In the case of other types of tumours, p53 is usually mutated and acts as a real oncogene. In the case of HPV infection, E6 suppresses the properties of p53 gene product, achieving the functional equivalent of the two hits required to knock out both alleles of a tumour suppressor gene. The mutations of p53 are normally not found. The E7 protein interacts with retinoblastoma protein $(\mathrm{pRb})$, which is the crucial factor for the cellular cycle control. This interaction causes the release of the transcription factor E2F, which is now free to act and can stimulate the cellular division. E7 is also able to bind and inactivate the protein kinase inhibitors p21 and p27 and can interact with different proteins whose significance has still not been determined ${ }^{[40,43]}$. Oral HPV infections have not been studied to the degree as those of the genital tract, although the evidence of association between certain tumours and HPV infection today is indisputable. Oncogenic HPVs are associated with oral malignancies, but its prevalence varies widely in different studies. Although study results are mixed, it seems possible that smoking and alcohol use may interact with HPV infection to increase a person's risk of oral cancer. So, oral HPV infections need to be studied and investigated deeply so that it can guide us for future cancer prevention programs, including oral HPV vaccination for oral HPV infections. HPV vaccination for oral HPV infections. Nevertheless, few studies have investigated the role of viruses in general and HPV in particularly in the aetiology of oral cancer in the Sudan. The first study investigated potentially malignant oral mucosal lesions from Sudanese patients (9 hyperplasias/40 dysplasias). HPV was found in only 2 Sudanese cases, both of which harboured both type 6 and type 11: both these cases demonstrated mild epithelial dysplasia [44]. Another study from Sudan investigated a total of 40 cases (patients with OSCCs) and 15 controls (patients with benign lesions) were included in the study. The cases included; carcinomas of the oral cavity proper, carcinomas of the lip vermilion. HPV was detected among $6(15 \%)$ of the cases, four were HPV type 16 and two were HPV type $18^{[45]}$. A recent study from Sudan reported the presence of HPV in head and neck cancers (HNCs) in general and in oral in particular. The study was performed on 150 samples of patients diagnosed with HNSCs. Six of the $150(4 \%)$ HNSCCs were HPV positive. HPV16 was the most prevalent type, with single infections present in 3/6 (50\%) cases, whereas HPV18 and HPV33 were detected in $2 / 6$ $(33 \%)$ and $1 / 6(17 \%)$, respectively. HPV infections were detected in $3(50 \%)$ cases of oral cavity and $3(50 \%)$ cases of pharynx ${ }^{[46]}$. Furthermore, very limited studies have investigated the role of other viruses such as, Epstein-Barr virus (EBV) and Herpes Simplex Virus (HSV) in the aetiology of oral cancer in Sudan beside HPV. Genetic factors have enhancing roles in many cancers including oral cancer. Limited studies have dealt with the investigation of association between genetic factors and level of risk for development of oral cancer in Sudan. A recent study investigated the prevalence of $\mathrm{p} 53$ codon 72 polymorphism in brush biopsies obtained from a Sudanese population. A total of 174 individuals were included in the study; chronic toombak users $(n=152)$ and non-users $(n=22)$. DNA was extracted from all the samples and genotyped for the codon 72 polymorphism by polymerase chain reaction/restriction fragment length polymorphism. The Arg/Pro genotype was found in $53 \%$ of the 174 study participants, compared to $21 \%$ found with Arg/Arg and 26\% found with Pro/Pro. Stratifying by toombak use, $28(18 \%), 45(29 \%)$ and $79(52 \%)$ of the 152 samples from toombak users had Arg/Arg, Pro/Pro and Arg/Pro respectively, compared to 9 (41\%), $0(0 \%)$ and 13 $(59 \%)$ found in the 22 samples from non users. The differences between the samples from toombak users and non 
users in Arg/Arg and Pro/ Pro codon 72 polymorphism and HPV infection were statistically significant $(\mathrm{P}<0.05)$. The study indicated that a high prevalence of the genotype Arg/Pro at the p53 codon 72 may contribute to susceptibility to OSCC, especially in combination with the use of carcinogenic tobacco-specific nitrosamine (TSNA)-rich toombak ${ }^{[47]}$.

To conclude Toombak is the major contributing factor for oral cancer in the Sudan being a potent carcinogenic factor,as well as acting as enhancing the carcinogenesis of other aetiological factors such as genetic factors and viruses. The role of Human Papilloma Virus in the aetiology of oral cancer can not be overlooked but the relation to Tombak use needs to be investigated. The role of other contributing factors such as viruses other than Human Papilloma Virus, other types of tobacco such as smoked tobacco and alcohol still need more investigations.

\section{References}

1. Early detection and prevention of oral cancer: a management strategy for dental practice. In: Edited by Paul Speight SW, Graham Ogden: British Dental Association, 2010.

2. Stewart B. WC: World cancer report 2014. Lyon: International Agency for Research on Cancer, World Health Organization, 2014.

3. Ferlay J, Soerjomataram I, Dikshit R, Eser S, Mathers C, Rebelo $\mathrm{M}$ et al. Cancer incidence and mortality worldwide: sources, methods and major patterns in GLOBOCAN 2012. I J Cancer. 2015; 136(5):E359-86.

4. Saeed IE, Weng HY, Mohamed KH, Mohammed SI. Cancer incidence in Khartoum, Sudan: first results from the cancer registry, 2009-2010. Cancer Med. 2014; 3(4):1075-84.

5. Petti S. Lifestyle risk factors for oral cancer. Oral Oncol. 2009; 45(4-5):340-50.

6. Patton LL, Elter JR, Southerland JH, Strauss RP. Knowledge of oral cancer risk factors and diagnostic concepts among North Carolina dentists. Implications for diagnosis and referra. J Am Dent Assoc. 2005; 136(5):602-10. quiz 682.

7. Patton LL. The effectiveness of community-based visual screening and utility of adjunctive diagnostic aids in the early detection of oral cancer. Oral Oncol. 2003; 39(7):708-23.

8. IARC. International Agency for Research on Cancer. IARC Monographs on the Evaluation of the Carcinogenic Risk of Chemicals to Humans, Vol. 37. Tobacco Habits other than Smoking; Betel Quid and Areca-nut Chewing; and some Related Nitrosamines, France, 1985.

9. Idris AM, Ahmed HM, Mukhtar BI, Gadir AF, el-Beshir EI. Descriptive epidemiology of oral neoplasms in Sudan 19701985 and the role of toombak. Int J Cancer. 1995; 61(2):155-8. [Medline: 7705940] [doi: 10.1002/ijc.2910610202].

10. Brunnemann KD, Genoble L, Hoffmann D. NNitrosamines in chewing tobacco: an international comparison. J. Agric. Food Chem. 1985; 33:1178-81. [doi: 10.1021/jf00066a039].

11. Idris AM, Nair J, Friesen M, Ohshima H, Brouet I, Faustman EM, Bartsch H. Carcinogenic tobacco-specific nitrosamines are present at unusually high levels in the saliva of oral snuff users in Sudan. Carcinogenesis. 1992; 13(6):1001-5. [Medline: 1600602] [doi: 10.1093/carcin/13.6.1001]
12. Tso TC. Physiology and Biochemistry of Tobacco Plants. Stroudsburg, PA: Dowden, Hutchinson and Ross, 1972, 393.

13. Andersen RA, Burton HR, Fleming PD, Hamilton-Kemp TR. Effect of storage conditions on nitrosated, acylated, and oxidized pyridine alkaloid derivatives in smokeless tobacco products. Cancer Res. 1989; 49(21):5895-900. [Medline: 2790803] [FREE Full Text].

14. Prokopczyk B, Wu M, Cox JE, Hoffmann D. Bioavailability of tobacco-specific N-nitrosamines to the snuff dipper. Carcinogenesis. 1992; 13(5):863-6. [Medline: 1587000] [doi: 10.1093/carcin/13.5.863].

15. Murphy SE, Carmella SG, Idris AM, Hoffmann D. Uptake and metabolism of carcinogenic levels of tobaccospecific nitrosamines by Sudanese snuff dippers. Cancer Epidemiol Biomarkers Prev. 1994; 3(5):423-8. [Medline: 7920210] [FREE Full Text].

16. Elbeshir EI, Abeen HA, Idris AM, Abbas K. Snuff dipping and oral cancer in Sudan: a retrospective study. Br J Oral Maxillofac Surg. 1989; 27(3):243-8. [Medline: 274281].

17. Idris AM, Ahmed HM, Malik MO. Toombak dipping and cancer of the oral cavity in the Sudan: a case-control study. Int J Cancer. 1995; 63(4):477-80. [Medline: 7591252] [doi: 10.1002/ijc.2910630402].

18. Ahmed HG, Idris AM, Ibrahim SO. Study of oral epithelial atypia among Sudanese tobacco users by exfoliative cytology. Anticancer Res. 2003; 23(2C):19439. [Medline: 12820484].

19. Ahmed HG, Diab WMI, Abdulgafar SA, Al-Hazmi AM. Role of quantitative Nuclear Cytomorphometric and NOR dots count in prediction of carcinogenic induced oral cellular proliferative activity. Oncocytology. 2011; 1:1-6. [doi: 10.5348/ocyj-2011-1-OR-1].

20. Hashibe M, Brennan P, Benhamou S, Castellsague X, Chen C, Curado MP et al. Alcohol drinking in never users of tobacco, cigarette smoking in never drinkers, and the risk of head and neck cancer: pooled analysis in the International Head and Neck Cancer Epidemiology Consortium. J Natl Cancer Inst. 2007; 99(10):77789. Erratum in: J Natl Cancer Inst. 2008; 100(3):225. Fernandez, Leticia [added]. [Medline: 17505073] [doi: 10.1093/jnci/djk179] [FREE Full Text].

21. Hecht SS. Tobacco carcinogens, their biomarkers and tobacco-induced cancer. Nat Rev Cancer. 2003; 3(10):733-44. Review. Erratum in: Nat Rev Cancer. 2004; 4(1):84. [Medline: 14570033] [doi: 10.1038/nrc1190].

22. IARC. Working Group on the Evaluation of Carcinogenic Risks to Humans. Tobacco smoke and involuntary smoking. IARC Monogr Eval Carcinog Risks Hum. 2004; 83:1-1438. [Medline: 15285078].

23. Idris AM, Ibrahim YE, Warnakulasuriya KA, Cooper DJ, Johnson NW, Nilsen R. Toombak use and cigarette smoking in the Sudan: estimates of prevalence in the Nile state. Prev Med. 1998; 27(4):597-603. [Medline: 9672954] [doi: 10.1006/pmed.1998.0331].

24. Seitz HK, Stickel F. Molecular mechanisms of alcoholmediated carcinogenesis. Nat Rev Cancer. 2007; 7(8):599-612. Review. [Medline: 17646865] [doi: $10.1038 / \mathrm{nrc} 2191]$.

25. Wiseman M. The second World Cancer Research Fund/American Institute for Cancer Research expert report. Food, nutrition, physical activity, and the prevention of cancer: a global perspective. Proc Nutr Soc. 
2008; 67(3):253-6. Epub 2008 May 1. Review. [Medline: 18452640] [doi: 10.1017/S002966510800712X].

26. Room R, Babor T, Rehm J. Alcohol and public health. Lancet. 2005; 365(9458):519-30. Review. [Medline: 15705462]

27. Ahmed HG, Ebnoof SO, Hussein MO, Gbreel AY. Oral epithelial atypical changes in apparently healthy oral mucosa exposed to smoking, alcohol, peppers and hot meals, using the AgNOR and Papanicolaou staining techniques. Diagn Cytopathol. 2010; 38(7):489-95. [Medline: 19894260] [doi: 10.1002/dc.21224].

28. Dysvik B, Vasstrand EN, Lųvlie R, Elgindi OA, Kross $\mathrm{KW}$, Aarstad HJ et al. Gene expression profiles of head and neck carcinomas from Sudanese and Norwegian patients reveal common biological pathways regardless of race and lifestyle. Clin Cancer Res. 2006; 12(4):110920. [Medline: 16489063] [doi: 10.1158/1078-0432.CCR05-0115] [FREE Full Text].

29. Ibrahim SO, Lillehaug JR, Dolphine O, Johnson NW, Warnakulasuriya KA, Vasstrand EN. Mutations of the cell cycle arrest gene p21WAF1, but not the metastasisinducing gene S100A4, are frequent in oral squamous cell carcinomas from Sudanese toombak dippers and nonsnuff-dippers from the Sudan, Scandinavia, USA and UK. Anticancer Res. 2002; 22(3):1445-51. [Medline: 12168821].

30. Jalouli MM, Jalouli J, Sapkota D, Ibrahim SO, Sand L, Hirsch JM. Differential expression of apoptosis, cell cycle regulation and intermediate filament genes in oral squamous cell carcinomas associated with toombak use in Sudan. Anticancer Res. 2011; 31(10):3345-51. [Medline: 21965745].

31. Ahmed HG, Mustafa SA, Eltom FM, Babiker AY. Frequency and genotype of human papillomavirus among Sudanese patients with head and neck tumours. Ecancermedicalscience. 2012; 6:282. Epub 2012 Dec 4. [Medline: 23226164] [doi: 10.3332/ecancer.2012.282] [FREE Full Text]

32. Mayne ST, Morse DE, Winn DM. Cancers of the oral cavity and pharynx. In: Schottenfeld D, Fraumeni Jr JF, editors. Cancer epidemiology and prevention. $3^{\text {rd }}$ ed. New York: Oxford University Press, 2006, 674-96. [doi: 10.1093/acprof:oso/9780195149616.003.0035].

33. Suliman NM, Astrųm AN, Ali RW, Salman H, Johannessen AC. Oral mucosal lesions in skin diseased patients attending a dermatologic clinic: a cross-sectional study in Sudan. BMC Oral Health. 2011; 11:24. [Medline: 21929814] [doi: 10.1186/1472-6831-11-24] [FREE Full Text].

34. Lucenteforte E, Garavello W, Bosetti C, La Vecchia C. Dietary factors and oral and pharyngeal cancer risk. Oral Oncol. 2009; 45(6):461-7. Epub 2008 Nov 5. Review. [Medline: 18990606] [doi: 10.1016/j.oraloncology.2008.09.002.

35. Chaudry AK, Singh M, Sundaram S, Mehrota R. Role of human papilloma virus and its detection in potentially malignant and malignant head and neck lesions: Updated review.Head and neck oncol. 2009; 1(1):22.

36. Silva KC, Rosa Ml, Moyse N, Afonso LA, Oliveira LH, Cavalcanti SM. Risk factors associated with human papillomavirus in two populations from Rio De Janeiro, Brazil Mem Inst Oswaldo Cruz. 2009; 104(6):885-891.

37. Hubbard RA. Human Papillomavirus testing methods. Arch Pathol lab Med. 2003; 127(8):940-945.

38. Brink AA, Snijders PJ, Meijer CJ. HPV detection methods. Dis Markers. 2007; 23(4):273-281.

39. Ibrahim Ginawi AM, Ebtihag Mahgoub A, Hussein Ahmed G. Immunophenotyping of HPV 16and 18 among Sudanese patients with oral lesions. Oman Medical Journal. 2012; 27(3):196-200. Doi.10.5001/omj2012.45.

40. Kumaraswamy KL, Vidhya M. Human papilloma virus and oral infections: an update. J Cancer Res Ther. 2011; 7(2):120-7. Review. [Medline: 21768696] [doi: 10.4103/0973-1482.82915].

41. Chang F, Syrjänen S, Kellokoski J, Syrjänen K. Human papillomavirus (HPV) infections and their associations with oral disease. J Oral Pathol Med. 1991; 20(7):305-17. Review. [Medline: 1654422] [doi: 10.1111/j.16000714.1991.tb00936.x].

42. Eversole LR. Papillary lesions of the oral cavity: relationship to human papillomaviruses. J Calif Dent Assoc. 2000; 28(12):922-7. [Medline: 11323946].

43. Gonzịlez Intxaurraga MA, Stankovic R, Sorli R, Trevisan G. HPV and carcinogenesis. Acta Dermatol. 2002; 11:3.

44. Ibrahim SO, Warnakulasuriya KA, Idris AM, Hirsch JM, Johnson NW, Johannessen AC. Expression of keratin 13, 14 and 19 in oral hyperplastic and dysplastic lesions from Sudanese and Swedish snuff-dippers: association with human papillomavirus infection. Anticancer Res. 1998; 18(1B):635-45. [Medline: 9584046].

45. Ahmed HG, Eltoom FM. Detection of Human Papilloma virus Types 16 and 18 among Sudanese patients with oral squamous cell carcinoma. The Open Cancer Journal. 2010; (3):1-5. [doi: 10.2174/1874079001003010130].

46. Ahmed HG, Mustafa SA, Eltom FM, Babiker AY. Frequency and genotype of human papillomavirus among Sudanese patients with head and neck tumours. Ecancermedicalscience. 2012; 6:282. Epub 2012 Dec 4. [Medline: 23226164] [doi: 10.3332/ecancer.2012.282] [FREE Full Text].

47. Sand L, Jalouli MM, Jalouli J, Sapkota D, Ibrahim SO. p53 Codon 72 polymorphism in oral exfoliated cells in a Sudanese population. In Vivo. 2012; 26(1):59-62. [Medline: 22210716]. 